\title{
Prevalence of Overweight and/or Obesity Among In-School Adolescents in Delta State, Nigeria
}

\section{Isikwenu Oghenefego*}

Department of Human Nutrition, University of Ibadan, Ibadan, Nigeria

*Corresponding Author: Isikwenu Oghenefego, Department of Human Nutrition, University of Ibadan, Ibadan, Nigeria.

Received: June 24, 2019; Published: July 12, 2019

DOI: $10.31080 /$ ASNH.2019.03.0369

\begin{abstract}
Adolescence is a period of accelerated growth and change, bridging the complex transition from childhood to adulthood. There has been a conscious or unconscious neglect of adolescents in most nutrition studies; which has resulted in a lot of diet-related health challenges arising among this age group. This study aimed to fill the knowledge gap and provide evidence and knowledge on prevalence of obesity among adolescents in Delta State. This study examined the dietary pattern and prevalence of overweight among in-school students in Delta state. A total of 400 hundred adolescent male and female aged between 11-19years took part in this study. Data was collect using a semi-structured questionnaire that included questions on socio-demography, food frequency, and anthropometry and activity level. 24-hour dietary recall was used to collect data on nutrient intake. Prevalence of overweight and obesity in the study population was found to be $9.3 \%$ and $4.5 \%$ respectively. Female had a higher prevalence of overweight and obesity compared to their male counterparts although there was no significant difference $(\mathrm{P}<0.05)$. Underweight was found to be a bigger problem than overweight or obesity in this population; with $50.5 \%$ prevalence. The need for nutrition education interventions and more research on adolescent nutrition is emphasized in this study. Health promotion interventions will help to reduce unhealthy dietary practices among youths, decreasing their risk for developing diet-related diseases and disorders that can detrimentally affect their lives.
\end{abstract}

Keywords: Adolescent; Malnutrition; Obesity; Underweight; Nigeria

\section{Introduction}

Adolescence is a period of accelerated growth and change, bridging the complex transition from childhood to adulthood. A wide variety of changes occur during the adolescent age which results in young people adopting behaviours that might have longterm effects on their health and well-being. Due to physiological, emotional and social changes, the teenage years can be described as a period of exploration, adventure and formation of personal ideologies. Adolescents have remarkable creativity, energy, and potential. There is no better time to begin adopting healthy behaviours that will enable them contribute positively to their communities. This is only possible when they are healthy, strong and productive. Adolescence is generally regarded as the period of life from puberty to maturity; the meaning of "puberty" and "maturity" are often debated by health professionals. Many adolescents begin puberty by age 10 , although there is significant individual variation in the developmental and maturation time line [1].

The growth spurt experienced during this phase of life is a risk factor for adolescents to develop eating disorders. Weight gain, increase in height, development of breasts, menarche and other changes in a female doubles the chances for self-esteem problems. It is understandably difficult for adolescents to accept these changes due to the fast pace with which they occur within a 6-8year period. This rapid physical growth and development is also responsible for the susceptibility of adolescents to life-threatening consequences if they experience semi-starvation. Every living thing suffers some level of harm when it does not receive the required amount of nutrients during periods of growth and development. Nutrients are essential for the proper building of tissues and energy is required for the process to be successful. Teenagers are not an exception to this principle; they need a healthy supply of nutrients for optimum growth and development (Ress, 2000).

In 1991, Delta State was created from the old Bendel State 27th August 1991 by General Ibrahim Babangida. Delta State is named after the delta region of the River Niger. Asaba is the capital city of the State which has other cities like Warri, Agbor, Ughelli and Sapele amongst others. Delta State has 25 local government areas and shares common boundaries with six other States namely, Edo, Ondo, Imo, Anambra, Rivers and Bayelsa States. There are five major ethnic groups in Delta State; Urhobo, Isoko, Itsekiri, Igbo and Ezon. 
As physiological requirements change with age, dietary habits are also influenced. Although the family's dietary intake strongly determines dietary habits in children, teenagers and adolescents have to struggle with contending influence from peer groups and food marketing. Moreno., et al. [2] opined that it is necessary to examine potential influences of age on dietary intake and body weight, consumption data throughout all age groups in childhood and in adolescence are necessary. At different points in the life cycle cognitive skills, social context and the ability to report dietary habits are challenges that mist be overcome to ensure accurate consumption data is gathered. Huang., et al. [3] pointed out that excluding implausible dietary reports is necessary for discerning dietary associations with BMI percentile. Energy intake and meal has a greater quantitative role in determining weight regulation as a child gets older as against snack pattern. This will be based on the premise that an older child will be more receptive to eating meals than when they were younger. Viner and Barker [4] showed that there was a higher association between adolescent risk factors and health outcome of adults than those found in childhood. This means that more attention needs to be paid to dietary patterns of adolescents to ensure they form the habit of eating healthy.

There is a difference in food intake pattern of adolescent males and females. In Australia, the 1995 National Nutrition Survey found that adolescent girls had a higher mean daily intake of fruits compared with males of the same age, and that boys tended to consume more soft drink than girls, with older boys (16-18 years) drinking twice as much as their female counterparts [5]. Presumably, due to the more rapid and obvious biological and physiological changes occurring in girls, they will be more health conscious as regards their food intake, while boys with increased activity levels might be more susceptible to ingesting quick energy fixes.

Data on recent regional differences in food intake patterns of adolescents are scarce. Adair and Popkin's [6,7] longitudinal study examined the food intake patterns of children and adolescents from four different countries (United States, Russia, China and the Philippines). Generally, adolescents in rural areas consumed less fast foods and soft drinks than their counterparts in urban areas; although this difference is said to have reduced over time. In another study, adolescents in urban areas were found to skip breakfast more often and eat more energy-dense foods than those in rural areas [8].

Must., et al. investigated, whether overweight in adolescents of age 13-18years was a good predictor for health problems in later ages and mortality. They found an association with an increased risk of mortality for all causes and disease-specific mortality among men, but not among women. The relative risks among men were 1.8 for mortality from all causes and 2.3 for mortality from coronary heart disease. The risk of morbidity from coronary heart disease and atherosclerosis was increased among men and women who had been overweight in adolescence. The report also showed that there was a higher risk of colorectal cancer among men while women who had been overweight in adolescence had a higher risk of arthritis. Interestingly, overweight in adolescence was a more powerful predictor of all the above mentioned risks than overweight in adulthood (Must., et al. 1992).

\section{Statement of problem}

The high prevalence of obesity in modern societies is a major public health threat and contributes to preventable morbidity and mortality. Current obesity rates among all age groups are two to three times higher than they were just 20years ago [9]. With 25\% if all North American children obese, attention to healthy habits has become a priority. For example, with increased prevalence of obesity nationally among adolescents, there has been a parallel increase in the incidence of Type 2 Diabetes. Adult obesity, CHD risks, breast cancer, morbidity and mortality have been associated with adolescent obesity [10].

Being overweight or obese increases the risk that adolescents will develop conditions such as diabetes, heart, lung and blood vessel disease that lead to early death. The reproductive system, general physical abilities, self-esteem and social life are often adversely affected by long-term overweight conditions.

\section{Justification of study}

Increasingly, measures of dietary patterns have been used to capture the complex nature of dietary intake and investigate its association with health. Certain dietary patterns may be important in the prevention of chronic disease; however, there are few investigations in adolescents [11]. Few studies have shown that the food intake pattern of adolescents are far from healthy; with majority lacking in fruits and vegetables, disproportionate amount of energy-dense foods (fatty snacks and soft drinks).

The adolescent stage is very important to focus on because they begin to gain autonomy from parental control in different aspects of their lives. They are given more liberty to decide what to eat, when to eat, at what frequency and quantity; their activity level and other decisions that might affect their health status now rest on them. It has also been noticed that this stage entails rapid physical development and young people try to attain their notion of acceptable body image. As adolescents, individuals begin to form personal health habits that can be carried on to adulthood [10].

Developmentally appropriate assistance to adolescents, particularly high-risk youth, including the homeless and incarcerated, helps them improve their nutritional habits and prepares them to live as productive adults who avoid many risks to health. Thus, understanding and promoting nutritional health during adolescence 
warrants renewed attention, followed by the allocation of resources for nutritional advocacy, training, research, and care [11].

From literature review, it has been discovered that there are no published articles on the study of adolescent dietary pattern and prevalence of obesity among adolescents in Delta state. Although there are articles of researches carried out in other states like Ogun, Oyo and Imo; they were carried out among children or pregnant women. There has been a conscious or unconscious neglect of adolescents in most studies; which has resulted in a lot of issues arising without solutions among this age group. This study will fill the knowledge gap and provide evidence and knowledge on adolescent dietary patterns and prevalence of obesity in Delta State.

\section{Relevance of nutrition to health}

Nutrition has been defined as the "Science of Food; the nutrients and the substances therein, their action, interaction, and balance in relation to health and disease; and the process by which the organism (e.g human body) ingests, digests, absorbs, transports, utilizes and excretes food substances" by the American Medical Association. Food provides the nutrients needed to fuel, build and maintain all body cells [12].

The study of nutrition is concerned about the body's metabolic and physiological response to diet. The scope of nutrition has broadened over the years with various advancements in molecular biology, biochemistry and genetics; biochemical pathways through which substances interact to maintain life is now been understood [13]. Good cognitive and spatial memory have been reported to be a result of improved awareness and practice of healthy eating habits.

\section{Nutrition in the life cycle}

Nutrition challenges vary as we progress through the life-cycle. Adequate nutrition for pregnant women and young children is essential for growth and healthy physical and mental development [14]. The nutritional health of a pregnant and lactating mother has far reaching effects on the health of her baby. In adulthood, the issues are different: the challenge is to avoid premature death or disability from diet-related chronic diseases and to progress into fit and healthy old age. It is however clear that these issues are interlinked. Good nutrition in early life-beginning with the fetal stage pays dividends in childhood and in later life. Furthermore, the impact of early nutrition on a young woman may; in turn, have an impact on the health of her children.

\section{Adolescent nutrition}

The World Health Organization defines adolescence as the segment of life between the ages of 10-19 years. Adolescents are a mid-life group, with some common nutrition problem with chil- dren and some with adults. In addition, there are adolescent-specific issues that call for specific strategies and interventions.

Adolescence represents an important life stage for the development of healthy nutrition behaviours; which have the tendency to determine health outcomes in adulthood. The nutritional demands associated with rapid physical and cognitive development and maturation are substantial $[15,16]$. In developed countries, adolescents increasingly demonstrate early signs of adverse nutrition-related conditions, including subclinical cardiovascular disease, type 2 diabetes, and obesity [17]. This is not far from the already existing obesity challenge noticed in North America. There is evidence that nutrition behaviors track from adolescence into adulthood [18]. Therefore, the promotion of healthy nutrition during adolescence has the potential to confer significant long-term health benefits.

Despite the importance of nutrition for adolescents' current and future health, many adolescents consume diets that are not consistent with dietary guidelines. For example, studies from the US, Europe, and Australia demonstrate that adolescents tend to have lower than desirable intakes of fruits, vegetables, dairy products, and whole grains but higher than desirable intakes of soft drinks, confectionery, and fast foods [11]. This might not be different for developing countries. Consequently, many adolescents fall short of achieving optimal nutrient intakes for good health and development.

A well-nourished adolescent today will become a highly productive, talented, energetic and responsible adult tomorrow. To achieve this, there must be a deliberate effort to break the cycle of malnutrition among adolescents.

There is no much difference in the nutrient needs of boys and girls before puberty. The advent of puberty triggers different biological changes which causes gender-specific nutrient needs. There is a significant increase in nutrient need for both genders during adolescence. Nutrient needs are equal to the rate of growth; with a peak in nutrient demand when growth velocity is highest. Nutritional requirements can go as high as double during adolescent growth spurt as against other periods of adolescence.

\section{Methodology}

Study design

This study is a cross-sectional, descriptive study.

\section{Study area}

This study was carried out in 2 local government areas; Oshimili South Local Government Area (Asaba, Urban) and Ndokwa West Local Government Area (Ogume and Emu-Obodeti, rural). 


\begin{tabular}{|l|c|c|c|c|}
\hline BMI-for-Age & Male \%(n) & Female \%(n) & Total \%(n) & $\mathbf{X}^{\mathbf{2}}$ \\
\hline Underweight & $53.0(106)$ & $48.0(96)$ & $50.5(202)$ & $2.049 \mathrm{a} 0.562$ \\
\hline Normal & $35.5(71)$ & $36.0(72)$ & $35.8(143)$ & \\
\hline Overweight & $7.5(15)$ & $11.0(22)$ & $9.3(37)$ & \\
\hline Obese & $4.0(8)$ & $5.0(10)$ & $4.5(18)$ & \\
\hline Total & $100(200)$ & $100(200)$ & $100(400)$ & \\
\hline
\end{tabular}

Table 2: BMI-for-Age of Adolescents by Sex in Delta State.

\begin{tabular}{|l|c|c|c|c|}
\hline \multicolumn{1}{|c|}{ MI-for-Age } & Oshimili South \%(n) & Ndokwa West \%(n) & Total \%(n) & $\mathbf{X}^{\mathbf{2}}$ \\
\hline Underweight & $50.0(102)$ & $51.0(102)$ & $50.5(202)$ & $6.169 \mathrm{a} 0.104$ \\
\hline Normal & $33.5(67)$ & $38.0(76)$ & $35.8(143)$ & \\
\hline Overweight & $9.5(19)$ & $9.0(18)$ & $9.3(37)$ & \\
\hline Obese & $7.0(14)$ & $2.0(4)$ & $4.5(18)$ & \\
\hline Total & $100(200)$ & $100(200)$ & $100(400)$ & \\
\hline
\end{tabular}

Table 3: BMI-for-Age of Adolescents by Local Government Areas in Delta State.

\section{Discussion}

Adolescent growth and development is closely linked to the diet they receive during childhood and adolescence. This study was designed to evaluate the prevalence of overweight and/or obesity among in-school adolescents in 2 local governments in Delta state.

In this study $4.5 \%$ of the study respondents were obese and $9.3 \%$ overweight as opposed to $50.5 \%$ who were underweight. In a similar study by Olumakaiye., et al. [19] in Osun state it was reported that the prevalence of underweight was $20.1 \%$ more common in rural $(22.1 \%)$ than urban adolescent (18.7\%). Also a study in Nigeria by Ansaa., et al. [20], reported the prevalence rates of obesity and overweight were $1.7 \%$ and $6.8 \%$, respectively among adolescents. This study clearly shows higher prevalence of overweight and obesity, and way higher underweight. Although there was no significant difference between rural and urban Local Government Areas (LGA), the rural LGA has slightly higher underweight prevalence than the urban LGA.

Ben-Bassey., et al. [21] reported a prevalence of overweight as $3.7 \%$ and obesity as 3.0\% among in-school adolescents in Eti-Osa LGA in Lagos state, Nigeria. This current study had higher prevalence of overweight and obesity, which indicates more adolescents are overweight and obese in Delta State than in Lagos. In comparison to similar studies by Wang., et al. [22] with similar age group, a higher prevalence of obesity was reported 6.5\% in Tehran. Wang's study clearly shows a closer prevalence of overweight and obesity with the current study. Dorosty., et al. [23] reported an Iranian prevalence of $15 \%$ for overweight and $5 \%$ for obesity among adolescents. Although the overweight prevalence for Iran is higher, there is a similarity in obesity prevalence with the current study. In a study among Indian adolescents prevalence of $11.1 \%$ overweight and $14.2 \%$ obesity was reported [24]. Over the past two decades, the prevalence of obesity among African-American adolescents ages 12 to 19 rose from 13.4 percent to 24.4 percent [25]. The reported differences in prevalence of overweight and obesity in other countries may be linked to the type of food and other environmental factors which are not peculiar to adolescents in Nigeria.

In this study, overweight and obesity is more prevalent in the female study sample compared to the male. Prevalence of overweight among female was $11 \%$ while male was $7.5 \%$; and this was not significantly different $(\mathrm{X} 2=2.049 \mathrm{a} ; \mathrm{P}=0.562)$. While the male respondents had a prevalence of $4.0 \%$ obesity, $5.0 \%$ of their female counterparts were obese. Akinpelu., et al. [26] reported a prevalence of overweight as $8.1 \%$ and obesity as $2.7 \%$ for male and $8.1 \%$ overweight and $1.9 \%$ obesity rates for female in a study among adolescents in Sagamu, Nigeria. This is very different from the results obtained in this study; obesity and overweight prevalence are clearly higher among male and female adolescents in Delta State. The variety of foods consumed in this region might be responsible for the obvious difference in anthropometric characteristics.

\section{Recommendation and Conclusion}

The Centers for Disease Control and Prevention (CDC) has identified unhealthy dietary patterns as one of the six categories of health behaviours that are linked to the leading causes of mortality and morbidity among all age groups in the United States [27].

This results show that more emphasis should be placed on curbing undernutrition in the study population, since there is a very high underweight prevalence. Although a fraction of this population are overweight or obese, underweight for this population is more of a public health issue. Review of anthropometric parameters is a simple way of evaluating the society's nutritional state and is a fundamental and applied pattern [28]. Although the prevalence of obesity was found to be low compared to some other parts of the 
world, interventions aimed at prevention of diet-related diseases and disorders should be developed and implemented targeting adolescents. Nutrition education for adolescents should be propagated at all levels and should form policies and programs for the health sector. The prevalence of underweight from this study is disturbing and concrete, conscious and strategic steps should be taken to curb this trend. Adolescents should be encouraged to engage in physical activity for healthy growth and wellbeing.

Parents have a responsibility to promote healthy eating in their households which can form a strong habit for adolescents before they leave home. "Junk foods" should be discouraged, while eating of fruits and vegetables should be encouraged at the family level. Educationists and policy makers should seek innovative ways to make healthy eating a desired and admired habit in our society.

Nutritionists and related public health researchers should give more attention to the study of adolescent nutrition, to reduce the knowledge gap and proffer solutions for improved service delivery in this field.

Health promotion interventions will help to reduce unhealthy dietary practices among youths, decreasing their risk for developing diet-related diseases and disorders that can detrimentally affect their lives.

Due to the scantiness of research materials on adolescent dietary pattern, dietary intake adequacy and prevalence of overweight/obesity in most parts of Nigeria, it is therefore recommended that more research be done in this area to close the knowledge gap and present more findings for appropriate interventions.

\section{Bibliography}

1. Mackay AP., et al. Adolescent Health Chartbook. National Center for Health Statistics, Maryland, United States (2000).

2. Moreno LA., et al. "How to Measure Dietary intake and food Habits in Adolescence: the European Perspective". International Journal of Obesity 29 (2005).

3. Huang TT-K., et al. "Energy intake and meal portions: Association with BMI percentile in US Children”. Obesity Research 12 (2004): 1875-1885.

4. Viner RM and Barker M. "Young People's Health: The Need for Action". BMJ (2005): 330-901-3.

5. Gayle S Savige., et al. "Food Intake Patterns Among Australian Adolescents". Asia Pacific Journal of Clinical Nutrition 16.4 (2007): 738-747.
6. Adair LS and Popkin BM. "Are Children Eating Patterns Being Transformed Globally?” Obesity Research 13 (2005): 12811299.

7. Popkin BM. "Nutritional Patterns and Transition, Population and Development". Review 19 (1993): 138-157.

8. Shiz Lien N., et al. "Sociodemographic Differences in Food Habits and Preferences of School Adolescents in Jiangs Province, China". European Journal of Clinical Nutrition 59 (2005): 14391448.

9. Heidi Wengreen and Cara Moncur. "Change in Diet, Physical activity and Body weight Among Young Adults during the Transition from High School to College". Nutrition Journal 8 (2007): 32.

10. Hams Kathleen Mullen, Rosalind Berkowitz King and Penny Gordon-Larsen (2003).

11. McNaughton Sarah A., et al. "Dietary Patterns of Adolescents and Risk of Obesity and Hypertension". Journal of Nutrition 138 (2008): 364-370.

12. Byrd-Bredbenner Carol., et al. Wardlaw's Perspectives in Nutrition, 8th ed., McGraw-Hill Int. L Ed. (2007): 658-670.

13. Berg J., et al. Biochemistry, 5th ed. n San Francisco: H.H. Freeman (2002): 603.

14. Food and Nutrition Bulletin (2000). 21.3 (2002): 28.

15. Rogol AD., et al. "Growth at Puberty". Journal of Adolescent Health 31 (2002): 192-200.

16. Spear BA. "Adolescent growth and development". Journal of the American Dietetic Association 102 (2002): S23-S29.

17. WHO Diet. Nutrition, and the prevention of Chronic diseases. Report of a Joint WHO/FAO Expert Consultation. WHO technical report series 916. Geneva's WHO (2003).

18. Lake AA., et al. "Longitudinal Changes in Food habits between adolescence (11-12years) and adulthood (32-33years): the ASH30 study". Journal of Public Health (Oxf) 28 (2006): 10-16.

19. Olumakaiye MF., et al. "Food Consumption patterns of Nigerian Adolescents and effect on body weight". Journal of Nutrition Education and Behavior 42 (2010): 144-151.

20. Ansaa Victor 0., et al. "Soft drink consumption and overweight/obesity among Nigerian adolescents". Obesity Reviews 3.4 (2008): 191-196. 
21. Ben-Bassey UP., et al. "Prevalence of overweight and obesity in Eti-Osa LGA, Lagos, Nigeria”. Obesity Reviews 8.6 (2007): 475-479.

22. Wang JW., et al. "Genetic and environmental correlations between obesity phenotypes and age at menarche". International Journal of Obesity 30 (2006): 1595-600.

23. Dorosty AR., et al. "Obesity in Iranian Children". Archives of diseases in Childhood 87 (2002): 388-391.

24. Chhatwal J., et al. "Obesity among pre-adeolscents and adolescents of developing country (India)". Asian Pacific Journal of Clinical Nutrition 13.3 (2004): 231-235.

25. Ogden CL., et al. "Prevalence and Trends in Overweight Among US Children and Adolescents, 1999-2000". Journal of the American Medical Association 288 (2002): 1728-1732.

26. Akinpelu AO., et al. "Overweight and Obesity: Does it Occur In Nigerian Adolescents". International Journal of Biomedical and Health Sciences 4.1 (2008).

27. Massey-Stokes Marilyn. "Adolescent Nutrition: Needs and Recommendations for Practice". JSTOR: The Cleaning House 75 (2002): 286-291.

28. Wang J., et al. "Anthropometry in body composition: an overview". Annals of the New York Academy of Sciences 904 (2000): 317-326.

\section{Volume 3 Issue 8 August 2019}

(C) All rights are reserved by Isikwenu Oghenefego. 